\title{
Impact of agricultural residual plastic film on the growth and yield of drip-irrigated cotton in arid region of Xinjiang, China
}

\author{
Can $\mathrm{Hu}^{1,2 \#}$, Xufeng Wang ${ }^{2 \#}$, Shiguo Wang ${ }^{3}$, Bing $\mathrm{Lu}^{1}$, Wensong Guo ${ }^{2}$, \\ Chaoji Liu², Xiuying Tang ${ }^{1 *}$ \\ (1. College of Engineering, China Agricultural University, Beijing 100083, China; \\ 2. College of Mechanical and Electrical Engineering, Tarim University, Alar 843300, Xinjiang, China; \\ 3. Xinjiang Academy of Agricultural and Reclamation Science Mechanical Equipment Research Institute, Shihezi 832000, China)
}

\begin{abstract}
Long-term and widespread use of plastic mulching has led to the accumulation of residual plastic film (RPF) in farmland soils of Xinjiang, China. However, there is no specific quantitative basis for RPF pollution or a clear understanding of the influence of residual film on crop growth. The aim of this study was to investigate the effect of RPF on the growth of cotton, an important cash crop of Xinjiang. Based on the field conditions and previous reports, various amount of residual film was applied in 0-30 cm soil layer. The growth index including emergence rate, dry matter, and yield of cotton was examined at different growth stages under different soil residual film levels. Results demonstrated a significant effect of RPF on soil moisture distribution and movement. Plastic residues had a significant effect on cotton growth at levels above $200 \mathrm{~kg} / \mathrm{hm}^{2}$, and the yield decreased as the RPF amount increased. Based on these findings, $200 \mathrm{~kg} / \mathrm{hm}^{2}$ was suggested as a threshold level to determine the effects of RPF on cotton. This study provided a basis to rate RPF pollution in farmland soils and help understand the impact of pollution on crop productivity.
\end{abstract}

Keywords: residual plastic film, plastic film pollution, soil pollution, pollution control, cotton, production management DOI: $10.25165 /$ j.ijabe.20201301.5084

Citation: Hu C, Wang X F, Wang S G, Lu B, Guo W S, Liu C J, et al. Impact of agricultural residual plastic film on the growth and yield of drip-irrigated cotton in arid region of Xinjiang, China. Int J Agric \& Biol Eng, 2020; 13(1): 160-169.

\section{Introduction}

Xinjiang Province covers an area of more than 160 million $\mathrm{hm}^{2}$ in China. Agricultural region of this province is around the Taklamakan desert, which is the second largest desert in the world. Due to the unique geographical environment, this region receives scanty rainfall and abundant sunlight, and oasis agriculture is practiced in this area. Xinjiang is the largest cotton producing area in China ${ }^{[1]}$, with snow on the Tianshan Mountain serves as the water source for cotton growth. However, oasis agriculture system in Xinjiang needs an increase in soil temperature and conservation of soil moisture. Therefore, plastic mulch is adopted to cover the soil surface. Mulching, which was firstly introduced in Xinjiang in 1980, has been widely applied in farming ${ }^{[6-8]}$. Plastic mulch preserves both soil heat and soil moisture ${ }^{[2,3]}$, significantly increases the yield of oasis agroecosystem ${ }^{[4,5]}$. Drip irrigation belt is laid under the mulch to supply water and fertilizer.

Received date: $2019-04-20 \quad$ Accepted date: 2020-01-08

Biographies: Can Hu, PhD candidate, Lecturer, research interests: intelligent agricultural equipment, Email: hucanboy1@qq.com; Xufeng Wang, PhD, Professor, research interests: agricultural equipment, residual film recovery, Email: wxfwyq@126.com; Shiguo Wang, Researcher, research interests: agricultural equipment, residual film recovery, Email: 362256015@qq.com; Bing Lu, $\mathrm{PhD}$ candidate, research interests: soil machinery, Email: 1170027843@ qq.com; Wensong Guo, PhD, Lecturer, research interests: soil machinery, Email: 541577947@qq.com; Chaoji Liu, PhD candidate, research interests: soil machinery, Email: 1719618835@qq.com.

\#These authors contributed equally to this work.

*Corresponding author: Xiuying Tang, $\mathrm{PhD}$, Professor, research interests: intelligent agricultural equipment. College of Engineering, China Agricultural University, Beijing 100083, China, Tel: +86-15910604652, Email: txying@ cau.edu.cn
Mulch placement time is from the beginning of sowing to the end of harvest. This method can reduce the influence of climate on crop growth to some extent.

In 2017, approximately 2800000 hectares of farmland were used for cotton cultivation and 198000 tons of plastic film was consumed in Xinjiang ${ }^{[9]}$. The long-term use of plastic films has contributed greatly to crop yield, but it also caused many problems. To reduce the initial investment, thin mulch film $(<0.01 \mathrm{~mm})$ and polyethylene blow molding have been widely used in Xinjiang. Mulch film is a plastic product, which loses its mechanical properties after one cultivation cycle. Moreover, it is difficult to mechanically or manually recover the mulch. The average recovery rate of mulch film is only $60 \%-85 \%$, and mulch film that hasn't been recovered was turned into smaller plastic debris and combined with soil to form the residue. The residual plastic film (RPF) was randomly distributed in the soil and distributed in strips, sheets and cylinders. Among them, when the RPF is fully expanded, majority of the RPF was in the size range of 4-20 cm. When water shrinks in the soil, it is generally in the shape of a cylinder or a long strip. Its shape diameter shrinks to about 1$1.5 \mathrm{~cm}$, and length is $4-8 \mathrm{~cm}$. Therefore, the approximate contact area of the RPF in the soil is $4-12 \mathrm{~cm}^{2}$. They interact with water and combine with soil, affecting soil texture. Researchers have found that the residual film was mainly and evenly distributed in the soil tillage layer in Xinjiang (0-30 cm in depth) after ploughing, and these particles, in turn, cause harmful effects on soil and crop. This phenomenon has been defined as residual plastic film pollution $^{[10-12]}$ and the agricultural plastic film fragments were called "residual film". The quantitative value of residual film is the total mass of residual film in a farmland area, which is referred to as the RPF amount. The effect of these pollutants on soil and crop isdefined as residual membrane pollution. 
RPF is regarded as the most important indicator of plastic film pollution $^{[13]}$. RPF has got accumulated in farmland soils over decades ${ }^{[14]}$, but the pollution hazards due to plastic film have been largely ignored. According to a survey conducted by author's research team, the mean amount of RPF in the cotton fields of Xinjiang is $216.88 \mathrm{~kg} / \mathrm{hm}^{2[15]}$. The heavily polluted areas include Shihezi, Aksu, Bortala Mongol Autonomous Prefecture, Tacheng Prefecture, Changji Prefecture, Hami City, and Kashi Prefecture $\left(\mathrm{RPF}>300 \mathrm{~kg} / \mathrm{hm}^{2}\right)$. Nowadays, plastic film pollution is receiving wide attention. Jin et al. reported ploughing, soil structure, and water movement that affected by plastic film residues ${ }^{[16]}$. Dong et al. found that artificial mixing of RPF influenced soil properties and water movement during farming ${ }^{[17]}$. Studies demonstrated $12.8 \%$ decrease in mean cotton yield when the density of residues was $600 \mathrm{~kg} / \mathrm{hm}^{2[18.19]}$. Hou et al. indicated the importance of a quantifiable index to judge the degree of soil pollution ${ }^{[20]}$ and to help improve the recovery of soil residual film. This quantitative value can be defined as the threshold above which residual film influences crop yield, emergence rate, dry matter, and other growth factors and adversely affects agricultural production. Due to the complexity of the environment, this threshold can only be obtained by field experiments; however, it is difficult to accurately simulate the field conditions in the laboratory. Chen proposed that RPF pollution assessment is conducive to agricultural production and the threshold value of RPF should be set according to local conditions $^{[21]}$. According to the Ministry of Agriculture of China, the threshold value of agricultural RPF is $75 \mathrm{~kg} / \mathrm{hm}^{2}$. The national standard for residual value of mulch film in farmland (GB/T 25413-2010) issued by the Ministry of Agriculture of China in 2010 focused on film fragments visible to the naked eye (size, $4-20 \mathrm{~cm}^{2}$ and contact area, $6 \mathrm{~cm}^{2}$ ). The standard specifies that the residual amount of mulch film is $75 \mathrm{~kg} / \mathrm{hm}^{2}$ of farmland, and states that when the residual value is $75 \mathrm{~kg} / \mathrm{hm}^{2}$, the residual film has little impact on crops. However, samples collected from different regions revealed that the actual amount of residue is far higher. This indicated the possibility of heavy pollution in Xinjiang with no drastic effect on yield and other growth indexes of cotton. Extensive use of chemical fertilizers and an increase in cotton seeding rate per hectare provide nutrition and maintain plant density. This counteracts with the effect of pollution caused by RPF and reduces farmers' concerns over this problem ${ }^{[22,23]}$. Therefore, some researchers believed that RPF may have only a small effect on crop yield. So far, few studies have demonstrated the relationship between RPF and crop growth. Therefore, this study was aimed to investigate the correlation, set a threshold value of agricultural RPF according to regional characteristics, and revise the threshold value for cotton in Xinjiang according to actual planting elements.

The aim of this study was to analyze the direct effect of RPF on cotton growth. Initially, the amount of RPF in the soil (0$30 \mathrm{~cm}$ ) of selected cotton fields of Xinjiang based on actual field conditions and previously collected data were determined. The experimental soil was divided into seven grades (T0-T7) based on the amount of residual film after mixing RPF fragments from the field with the soil of the experimental area. All experimental sites were covered with plastic film, and water and fertilizer were delivered by drip irrigation. The cotton growth indexes, such as emergence rate, dry matter content, and yield during different growth stages and at different RPF levels, was measured to investigate the impact of RPF. The findings of this study will provide the basis to assess RPF pollution and help reduce pollution.

\section{Materials and methods}

\subsection{Experimental site and materials}

2.1.1 Selection of the experimental site

The field experiment was conducted during 2017-2018 at the No. 18 Laboratory Site $\left(151.2 \mathrm{~m}^{2}\right)$, Alar City, Xinjiang $\left(40^{\circ} 33^{\prime} \mathrm{N}\right.$, $81^{\circ} 10^{\prime} \mathrm{E}$; elevation, $1031 \mathrm{~m}$ ) (Figure 1a). This area is characterized by an arid continental climate. The mean annual sunshine duration was $2990 \mathrm{~h}$, the mean annual temperature was $11.4^{\circ} \mathrm{C}$, the frost-free period was $180-210$ days, and the mean annual rainfall was $58.6 \mathrm{~mm}$. Temperature and rainfall during the experiment are shown in Table 1. The temperature of this area remained stable throughout the year with no extreme weather. The average duration of sunshine from April to October was $9.5 \mathrm{~h}$, which is suitable for long staple cotton and fine staple cotton cultivation. During the experimental period, the sunshine time and rainfall are similar to those in the past three years, there was no extreme weather, and the natural climate conditions were stable. Moreover, when mulching and drip irrigation under mulch were used, the crop growth conditions were stable and suitable for repeated plot experiments. Therefore, the repeatability experiment in this period was used as the evaluation experiment of the effect of RPF on cotton growth. The experimental period was from April 10, 2018 (sowing date) to October 20, 2018 (193 days). Seedling emergence was on April $21^{\text {st }}$, flowering on July $7^{\text {th }}$, and boll opening on September $15^{\text {th }}$. The soil was aridisols according to USDA soil taxonomy. The soil $\mathrm{pH}$ was 8.55 and the soil conductivity was $1.91 \mathrm{~s} / \mathrm{m}$ (top layer, $0-30 \mathrm{~cm}$ ). The available nitrogen, available phosphorus, available potassium, and organic matter contents in the soil were $77.61 \mathrm{mg} / \mathrm{kg}, 23.33 \mathrm{mg} / \mathrm{kg}$, $151.02 \mathrm{mg} / \mathrm{kg}$, and $1.62 \%$, respectively.

Table 1 Temperature and rainfall in the field during the experiment

\begin{tabular}{ccccccc}
\hline Month & $\begin{array}{c}\text { Maximum } \\
\text { temperature } \\
/{ }^{\circ} \mathrm{C}\end{array}$ & $\begin{array}{c}\text { Minimum } \\
\text { temperature } \\
/{ }^{\circ} \mathrm{C}\end{array}$ & $\begin{array}{c}\text { Rainfall } \\
/ \mathrm{mm}\end{array}$ & $\begin{array}{c}\text { Rainfall } \\
\text { times/d }\end{array}$ & $\begin{array}{c}\text { Rainstorm } \\
\text { and hail }\end{array}$ & $\begin{array}{c}\text { Average } \\
\text { temperature } \\
/{ }^{\circ} \mathrm{C}\end{array}$ \\
\hline April & 26 & 6 & 0 & 0 & 0 & 13 \\
May & 33 & 9 & 2.2 & 1 & 0 & 16.2 \\
June & 34 & 13 & 9.4 & 2 & 0 & 20.8 \\
July & 36 & 14 & 17.3 & 5 & 0 & 23.5 \\
August & 35 & 15 & 11.7 & 3 & 0 & 24.8 \\
September & 30 & 8 & 8.9 & 2 & 0 & 20.2 \\
October & 36 & -3 & 0 & 0 & 0 & 12.2 \\
\hline
\end{tabular}

Note: The experimental period was from April 10 to October 20, 2018 (193 d) 2.1.2 Cotton seeds and RPF

Seeds of the cotton accession 'Xinluzao No. 33' were used (germination rate $=97 \%$ ) in this study. RPF samples were collected from farmlands where plastic mulching was continuously practiced for more than 10 years (Figure 1b). The residual film samples were strip-like and were evenly distributed in the soil by artificial mixing. The actual size of the RPF was a random sheet shape of 4-20 cm. When it shrinks in the soil layer, it was generally a strip shape or a cylinder shape. The contact area between the two sides of the whole shrinking cylinder shape and the soil was about $4-12 \mathrm{~cm}^{2}$. Because of the randomness of the shape and size of the residual membrane, three sizes were selected as the samples of the RPF. The first sample was $3 \mathrm{~cm}$ in width and $5 \mathrm{~cm}$ in length when it was expanded and $5 \mathrm{~cm}^{2}$ when it was contracted in soil. The second sample was $3 \mathrm{~cm}$ in width and $8 \mathrm{~cm}$ in length, and $8 \mathrm{~cm}^{2}$ in soil shrinkage. The third sample was $3 \mathrm{~cm}$ in width and $10 \mathrm{~cm}$ in length when it is expanded and $10 \mathrm{~cm}^{2}$ when 
it was contracted in soil. These three samples were either shrunk or stretched under the influence of soil, water, and other factors that made the actual area of contact between the residual film and the soil close to $6 \mathrm{~cm}^{2}$. The RPF samples were collected from soil (0-30 cm layer) before sowing. Fig 1c shows pieces of RFP that takes on a long strip shape as it contracts in the soil. The RFP was mixed in $0-30 \mathrm{~cm}$ soil according to the experimental proportion to study the effect of RPF on crops.

\subsubsection{Experimental tools}

A German-made 11ftt-550 hydraulic high-speed plow and a Canadian-made 1jpd-3000 soil preparation machine were used to make the soil flat before sowing, and the ploughing depth was $30 \mathrm{~cm}$ so that the residual film was distributed evenly in the soil layer after cultivation. Seeds were sown using $2 \mathrm{BMJ}-8 / 2$, a precise mulching and seeding machine, developed by Xinjiang Keshen Co., Ltd. This machine combines precision sowing, mulching, drip belt laying and other processes, and can complete the laying of drip belt under the film, hole drilling on the film and mulching at the same time, as shown in Figure 1e. Other tools used in the experiment were shovel, spade, sieve (mesh number = 10 , mesh size $=2 \mathrm{~mm}$ ), pegwood (length $=50 \mathrm{~cm}$ ), position line, tapeline, bag, electronic balance (BT125D; precision: $0.001 \mathrm{~g}$; Sardo company), soil temperature/humidity detector (TDC-220D

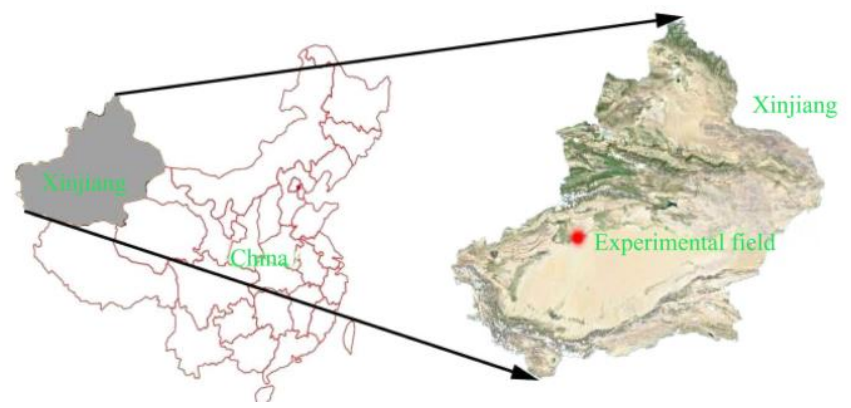

a. Experiments were conducted in the No. 18 Laboratory Site, Farms in Alar City, Xinjiang type sensor; Beijing time Technology Co., Ltd.), and digital caliper.

\subsection{Experimental methods}

Seeds were sown on March 29, 2018, during the spring seeding period in Xinjiang, using the mulching and seeding machine after ploughing (depth of $30 \mathrm{~cm}$ ) and seed bed preparation. The experimental field $\left(120 \mathrm{hm}^{2}\right)$ was divided into seven blocks that represented seven treatments, and each block was divided into three plots for three replicates. The width of a plastic film was $2000 \mathrm{~mm}$, in which cotton was arranged in twin row. In each twin row, the distance between cotton rows was $100 \mathrm{~mm}$, the distance between twin rows was $660 \mathrm{~mm}$, and $100 \mathrm{~mm}$ gap between plants was set on both sides of the twin row of cotton on the most edge. The redundant side membranes on both sides were firmly embedded in the soil to ensure contact between the membrane and the soil (Figure 1f). During the experiment, the drip irrigation belt was set under the mulch, and one drip irrigation belt was placed in each twin row of cotton on the surface of the soil. The field was managed in a routine way using drip irrigation, which provided water and fertilizer for cotton. The drip irrigation belt was set under the mulch, and one drip irrigation belt was set for every two rows of cotton on the surface of the soil. Irrigation was first done $\left(130.5 \mathrm{~m}^{3} / \mathrm{hm}^{2}\right.$; once) for seed emergence and thereafter, twice a month $\left(364.125 \mathrm{~m}^{3} / \mathrm{hm}^{2}\right.$; total 12 times).

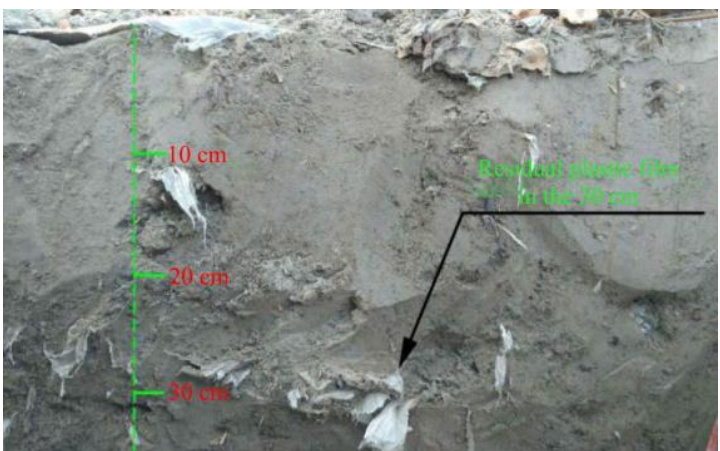

b. Residual plastic film in the $0-30 \mathrm{~cm}$ soil layer of the selected cotton field

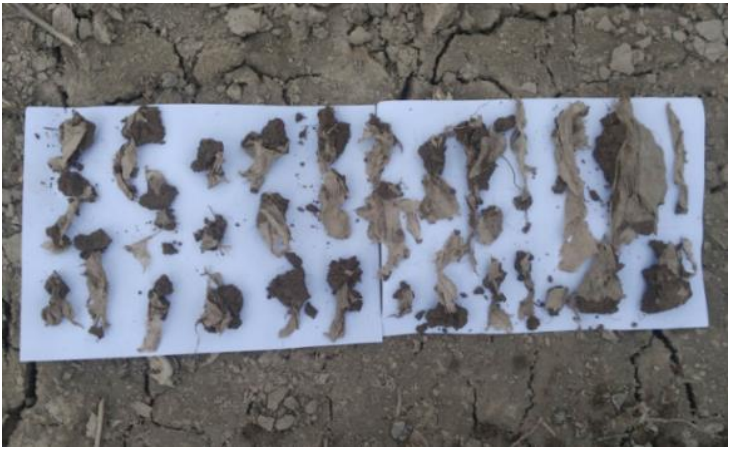

c. Residual plastic film samples in soil

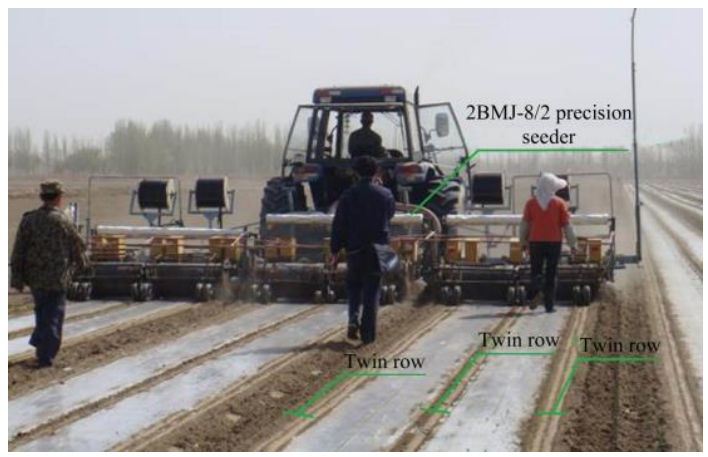

e. Mulching and sowing

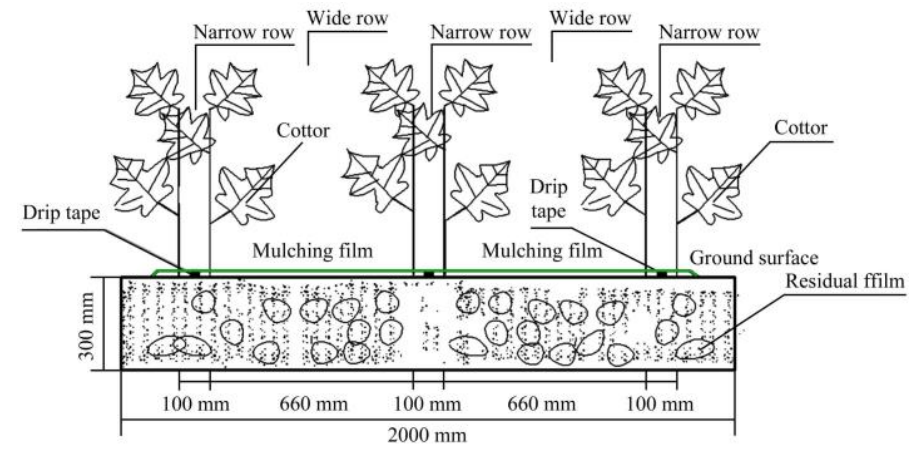

d. Planting pattern of $(660+100) \times 100 \mathrm{~mm}$

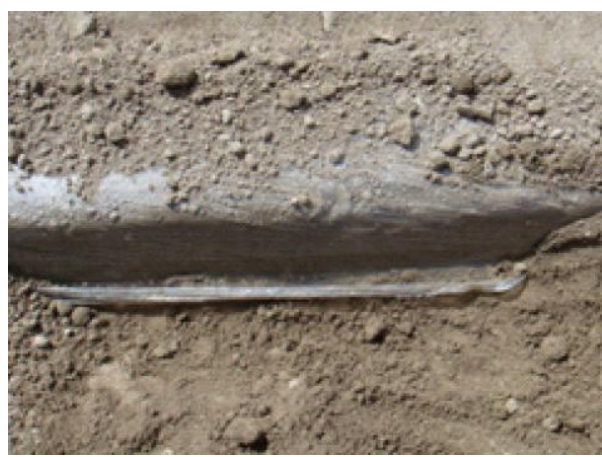

f. Edge film of mulch is buried in the soil

Figure 1 Experimental site and residual plastic film samples 
Based on earlier studies, RPF of three different sizes ${ }^{[24,25]}$ were uniformly mixed into the soil at a mass ratio of $1: 1$. The RPF samples were taken from the periphery of the site and were evenly mixed into the $0-30 \mathrm{~cm}$ soil layer after pre-sampling. Seven RPF levels (T0, T1, T2, T3, T4, T5, and T6; T0 represents the ideal state of cotton growth that is free from the effect of RPF) were applied according to the film size and density, planting years, and the actual value of plastic film residue of selected cotton fields in Xinjiang $^{[24]}$ (Table 2). In T0 set, the RPF in the experimental plot was removed to avoid residual membrane influence. The residual membrane in other areas was set based on the RPF ratio. The residual film in $\mathrm{T} 1$ experimental area was set to $7.5 \mathrm{~g} / \mathrm{m}^{2}$ (the depth of sample treated soil was $0-30 \mathrm{~cm}$ ), and the residual film in T2 experimental area was set to $15 \mathrm{~g} / \mathrm{m}^{2}$ (the depth of sample treated soil was 0-30 cm). Two repeat groups were maintained simultaneously, in which one of them served as control.

Table 2 Residual plastic film levels used in the experiment. Seven gradient amounts of residual plastic film were used in the experiment denoted by T0, T1, T2, T3, T4, T5, and T6

\begin{tabular}{ccc}
\hline Number & $\mathrm{RPF} / \mathrm{kg} \cdot \mathrm{hm}^{-2}$ & Test number \\
\hline 1 & 0 & $\mathrm{~T} 0$ \\
2 & 75 & $\mathrm{~T} 1$ \\
3 & 150 & $\mathrm{~T} 2$ \\
4 & 250 & $\mathrm{~T} 3$ \\
5 & 350 & $\mathrm{~T} 4$ \\
6 & 500 & $\mathrm{~T} 5$ \\
7 & 800 & $\mathrm{~T} 6$ \\
\hline
\end{tabular}

In addition, replicate test plots were maintained for each treatment to verify the accuracy of the results. During seedling stage and boll set stage, three similar plants were removed from each plot and a total of nine plants were selected for each RPF amount to analyze root characteristics and dry matter content (Figure 2).

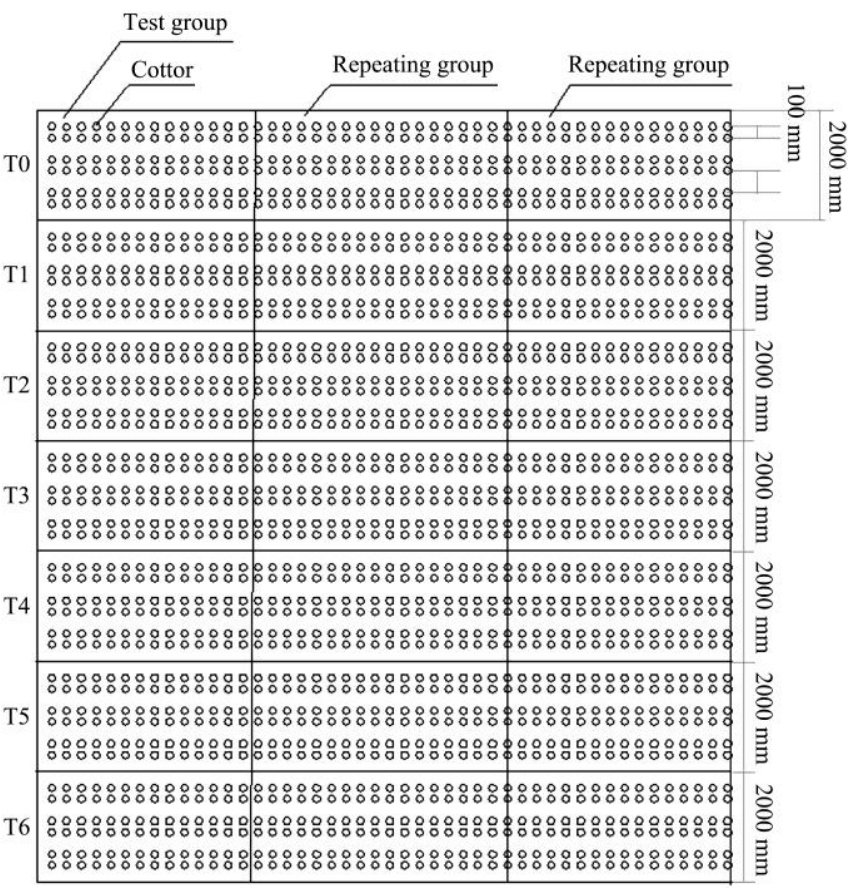

Note: T0-t6 group was set up in the experiment, and each group was set up with a repetition group to facilitate the experiment comparison and data measurement. The width of each group is $2000 \mathrm{~mm}$, and a repeat group is set every $20 \mathrm{~m}$.

Figure 2 Schematic diagram of the field experiment. T0 to T6 represent the different experimental groups

\subsection{Sampling and measurement of indexes}

\subsubsection{Root volume and root length}

Root samples were collected during the seedling stage (May 15, 2018 ) and the boll set stage (July 15, 2018). $0.003 \mathrm{~m}^{3}$ soil $(10 \mathrm{~cm}$ long, $10 \mathrm{~cm}$ wide and $30 \mathrm{~cm}$ deep) was dug out by trench method from the area around the plant to obtain each root sample. At the inner $1 / 3-1 / 2$ of the outer edge of cotton seedlings, trenches $(10 \times$ $10 \times 30 \mathrm{~cm}$ ) were dug that formed a cutting line with the crown diameter. The soil was divided into three different layers $(0-10 \mathrm{~cm}$, $10-20 \mathrm{~cm}$, and $20-30 \mathrm{~cm}$ ). The roots were collected, cleaned with water, and dried with filter paper. The root volume was measured by drainage method using a measuring cylinder. The measuring cylinder $(300 \mathrm{~mL})$ was firstly filled with $100 \mathrm{~mL}$ pure water. The root system was completely immersed to give the root volume. To measure the root length, five root systems were selected from the samples, including long, short and medium root to get the average value.

\subsubsection{Dry matter content}

Sampling was done at the end of the seedling stage and the boll set stage. Roots, stems, leaves, flowers, and fruits were separated from each sample. After deactivation at $105^{\circ} \mathrm{C}$ for $30 \mathrm{~min}$, the organs were dried at $80^{\circ} \mathrm{C}$ until a constant weight was obtained.

\subsubsection{Plant height and stem diameter}

Sampling was done $60 \mathrm{~d}$ after sowing at a frequency of once a week. A tapeline was used to measure the root length and the plant height. A digital caliper was used to measure the diameter of the main stem. From each control group, crown height of 20 groups was measured and the average was calculated.

2.3.4 Root dry weight density and root length density

Root dry weight density and root length density were calculated as follows:

$$
\begin{gathered}
D_{m}=\frac{W}{V_{1}} \\
D_{l}=\frac{L}{V_{1}}
\end{gathered}
$$

where, $D_{m}$ represents the root dry length density $\left(\mathrm{g} / \mathrm{m}^{3}\right)$ of the 0 $30 \mathrm{~cm}$ soil layer; $D_{l}$ represents the root length density $\left(\mathrm{m} / \mathrm{m}^{3}\right)$ of the 0-30 cm soil layer; $W$ represents the root dry weight $(\mathrm{g})$ of the 0 $30 \mathrm{~cm}$ soil layer; $V_{1}$ is $0.003 \mathrm{~m}^{3}$ (volume of soil in the trench), and $L$ represents the root length $(\mathrm{cm})$ of the $0-30 \mathrm{~cm}$ soil layer.

\subsubsection{Yield index}

Cotton samples were harvested three times based on maturity. Samples from different plots were separately collected, weighed and preserved. Statistics on the amount of cotton harvested from the experimental field and the mean amount of cotton collected from each experimental plot were collected.

2.3.6 Data processing and statistical analysis

AutoCAD 18.0 (2010) was used to draft the experimental field. OriginPro 8.5.1 was used for drawing and function fitting. SPSS 19.0 was used for variance analysis and multiple comparisons (LSD).

\section{Results and discussion}

\subsection{Effect of RPF on soil moisture}

The distribution of soil moisture content in different plough layers $(0-10 \mathrm{~cm}, 10-20 \mathrm{~cm}, 20-30 \mathrm{~cm})$ in the test area was shown in Table 3. In each experimental group, the humidity of T0 and T1 groups increased gradually in $0-30 \mathrm{~cm}$ soil layer. The average humidity was $19.8 \%$ in $0-10 \mathrm{~cm}$ soil layer, $21.45 \%$ in $10-20 \mathrm{~cm}$ soil layer, and $21.92 \%$ in $20-30 \mathrm{~cm}$ soil layer. The results showed that 
with the small amount of RPF in the T0 and T1 experimental groups, the infiltration of water and fertilizer in the soil was uniform, and the water and fertilizer could reach the cultivation layer $(0-30 \mathrm{~cm})$ of crops normally. In the T2-T6 experimental group, the humidity value changed significantly in the $10-20 \mathrm{~cm}$ soil layer, showing that the $10-20 \mathrm{~cm}$ soil humidity value was higher than the $20-30 \mathrm{~cm}$ soil layer. This was related to the movement of water in the soil layer. The water was permeated to the surface of soil by drip irrigation belt and then moved down. However, residual film can hinder the downward movement of water, and make an uneven distribution of water in different soil layers. Water in the soil without the influence of RPF can move down faster, which makes the water and fertilizer reach the root system of crops quickly.

Table 3 Moisture distribution measured in 0-30 cm soil layer

\begin{tabular}{|c|c|c|c|c|c|c|}
\hline $\begin{array}{l}\text { Soil } \\
\text { layer }\end{array}$ & RPF & $\begin{array}{l}\text { Measurement } \\
\text { point } 1\end{array}$ & $\begin{array}{l}\text { Measurement } \\
\text { point } 2\end{array}$ & $\begin{array}{l}\text { Measurement } \\
\text { point } 3\end{array}$ & $\begin{array}{l}\text { Measurement } \\
\text { point } 4\end{array}$ & $\begin{array}{l}\text { Measurement } \\
\text { point } 5\end{array}$ \\
\hline \multirow{7}{*}{$\begin{array}{c}0- \\
10 \mathrm{~cm}\end{array}$} & T0 & 19.54 & 19.92 & 20.03 & 19.81 & 20.16 \\
\hline & $\mathrm{T} 1$ & 19.83 & 20.04 & 20.81 & 20.19 & 20.06 \\
\hline & $\mathrm{T} 2$ & 20.90 & 20.21 & 21.88 & 20.15 & 20.37 \\
\hline & $\mathrm{T} 3$ & 21.23 & 21.88 & 21.93 & 20.64 & 20.61 \\
\hline & $\mathrm{T} 4$ & 21.08 & 22.86 & 21.24 & 21.31 & 21.32 \\
\hline & T5 & 21.98 & 22.08 & 22.16 & 22.29 & 21.43 \\
\hline & T6 & 22.22 & 23.01 & 22.30 & 23.47 & 22.96 \\
\hline \multirow{7}{*}{$\begin{array}{c}10- \\
20 \mathrm{~cm}\end{array}$} & T0 & 21.22 & 21.30 & 21.80 & 22.06 & 20.90 \\
\hline & $\mathrm{T} 1$ & 20.88 & 21.21 & 21.41 & 20.89 & 21.30 \\
\hline & $\mathrm{T} 2$ & 22.30 & 20.95 & 21.19 & 22.07 & 22.18 \\
\hline & $\mathrm{T} 3$ & 23.06 & 22.51 & 22.82 & 22.94 & 23.11 \\
\hline & $\mathrm{T} 4$ & 23.90 & 24.02 & 23.88 & 23.67 & 23.91 \\
\hline & T5 & 25.02 & 24.31 & 24.80 & 24.13 & 25.10 \\
\hline & T6 & 24.16 & 24.09 & 23.63 & 23.57 & 22.91 \\
\hline \multirow{7}{*}{$\begin{array}{c}20- \\
30 \mathrm{~cm}\end{array}$} & T0 & 22.32 & 21.84 & 21.37 & 21.99 & 22.07 \\
\hline & $\mathrm{T} 1$ & 23.11 & 23.08 & 22.19 & 22.67 & 21.97 \\
\hline & $\mathrm{T} 2$ & 20.11 & 20.85 & 20.16 & 19.29 & 20.37 \\
\hline & $\mathrm{T} 3$ & 20.84 & 19.28 & 19.81 & 20.54 & 19.83 \\
\hline & $\mathrm{T} 4$ & 21.08 & 20.31 & 19.87 & 19.65 & 20.61 \\
\hline & T5 & 20.20 & 20.11 & 20.77 & 18.97 & 19.53 \\
\hline & T6 & 19.68 & 20.10 & 19.86 & 20.54 & 20.31 \\
\hline
\end{tabular}

3.2 Effects of RPF on germination rate and seedling survival rate

Cotton yield was closely related to survival rate, which refers to the probability of cotton seedling survival after germination. Distribution of RPF is a key factor that influences cotton growth and an important index to evaluate the effect of RPF on seed germination and seedling survival (Figure 3). Meanwhile, an even distribution of residual film in the soil was expected to prevent its adverse effects on nutrient absorption, root growth, and ultimately plant growth and yield. Multiple comparisons using LSD performed that germination rate and seedling survival rate were significantly different between different RPF levels, while T0 was selected as the reference group, using 240 plants to optimize the reference group results (Table 4). In general, germination rate showed a negative correlation with the amount of RPF. At lower levels (T1-T2), RPF had no significant effect on the germination rate. From T3 RPF level, the germination rate started to be significantly less than that for T0 $(F=2.93, p<0.05)$. Therefore, the RPF amount used in T3 was considered a key level to rate pollution.
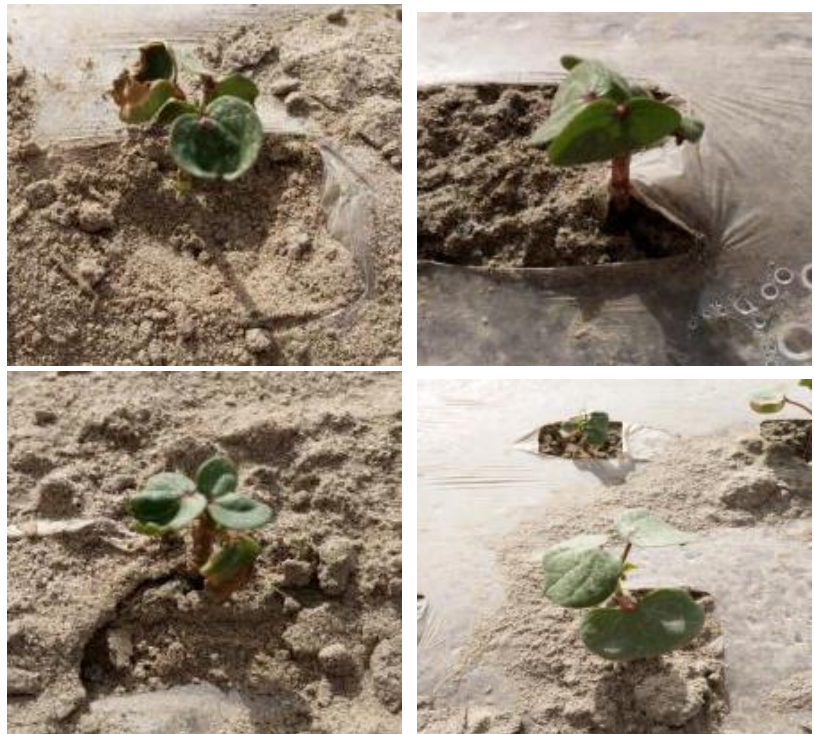

Figure 3 Cotton germination in the experimental field

Table 4 Effects of different gradient amounts of RPF on germination rate and survival rate

\begin{tabular}{cccccc}
\hline RPF & $\begin{array}{c}\text { Plant } \\
\text { number }\end{array}$ & $\begin{array}{c}\text { Germination } \\
\text { number }\end{array}$ & $\begin{array}{c}\text { Survival } \\
\text { number }\end{array}$ & $\begin{array}{c}\text { Germination } \\
\text { rate/\% }\end{array}$ & $\begin{array}{c}\text { Survival } \\
\text { rate/\% }\end{array}$ \\
\hline T0 & 240 & 221 & 198 & 92.08 & 82.50 \\
T1 & 120 & 106 & 97 & 88.33 & 80.83 \\
T2 & 120 & 106 & 99 & 88.33 & 82.51 \\
T3 & 120 & 101 & 94 & 84.16 & 78.33 \\
T4 & 120 & 94 & 77 & 78.33 & 64.16 \\
T5 & 120 & 89 & 71 & 74.16 & 59.16 \\
T6 & 120 & 82 & 61 & 68.33 & 50.83 \\
\hline
\end{tabular}

At this threshold level, the survival rate of cotton seedlings showed a negative correlation with the amount of RPF. From T1 to T6, the survival rates decreased by $2.02 \%,-0.012 \%, 5.06 \%$, $22.23 \%, 28.29 \%$, and $38.39 \%$ respectively compared to T0. RPF had no significant effect on the seedling survival rate at levels below $250 \mathrm{~kg} / \mathrm{hm}^{2}$. The seedling survival rate for T4-T6 (250$350 \mathrm{~kg} / \mathrm{hm}^{2}$ ) were significantly decreased compared to other treatments $(F=2.66, p<0.05)$. Therefore, an RPF level of $250 \mathrm{~kg} / \mathrm{hm}^{2}$ was considered as a key to determine the threshold limit value of RPF.

\subsection{Effect of RPF on root growth}

\subsubsection{Root volume}

RPF below $250 \mathrm{~kg} / \mathrm{hm}^{2}$ showed no significant effect on cotton growth during the seedling stage $(F=0.35, p>0.05)$. However, the root volume was significantly decreased when RPF level increased to above $250 \mathrm{~kg} / \mathrm{hm}^{2}(F=2.93, p<0.05)$ (Figure 4). From T1 to T6, root volume decreased by $8.61 \%, 16.44 \%, 20.08 \%$, $37.33 \%, 43.6 \%$, and $74.38 \%$ respectively compared to T0, which indicated the significant negative effect of RPF on root volume.

During the boll set stage, the root volume decreased with increasing RPF level. From T1 to T6, 4.4\%, 9.33\%, 18.27\%, $28.83 \%, 57.34 \%$, and $68.77 \%$ decrease of root volume compared to T0 was observed. The root volume during the seedling stage decreased faster than during the boll set stage, which indicates a greater effect of RPF on root volume during the seedling stage.

\subsubsection{Root length density}

To quantitatively analyze the effect of RPF on cotton growth, the weekly growth rates were calculated during the seedling stage and the boll set stage. Above a threshold level, the growth rate of plant height demonstrated a negative correlation with the amount of 
RPF. At $250 \mathrm{~kg} / \mathrm{hm}^{2}$, the root length density, during both the seedling stage and the boll set stage, significantly decreased under the effect of RPF. This may be because the residues block soil infiltration, makes the moisture remains in the topsoil and gets evaporated, which in turn inhibits plant growth.

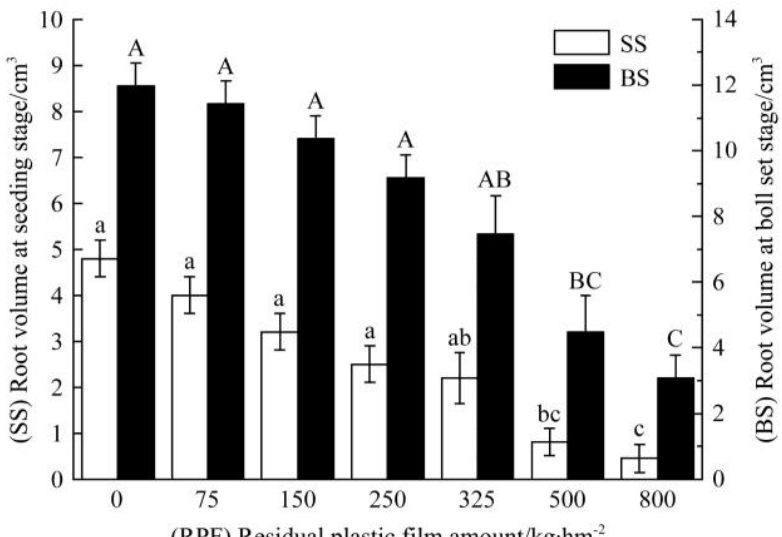

Note: Different lowercase letters indicate a significant difference between the gradient levels in the seedling stage (SS) $(p<0.05)$. Different uppercase letters indicate a significant difference between the gradient levels in the boll set stage (BS) $(p<0.05)$.

Figure 4 Effects of residual plastic film on root volume during the seedling stage (SS) and the boll set stage (BS)

From $\mathrm{T} 1$ to $\mathrm{T} 6$, the root length density was decreased by $8.69 \%, 13.04 \%, 20.65 \%, 31.52 \%, 40.21 \%$, and $40.86 \%$ during the seedling stage and by $5.63 \%, 7.9 \%, 13.15 \%, 22.34 \%, 32.47 \%$, and $35.51 \%$ during the boll set stage compared to T0 (Figure 5). During both the seedling stage and the boll set stage, the root length density was significantly lower than that in control group when RPF levels above $250 \mathrm{~kg} / \mathrm{hm}^{2}(p<0.05)$. The root length density during the seedling stage decreased faster than during the boll set stage, which may indicated a greater effect of RPF on root length density during the seedling stage.

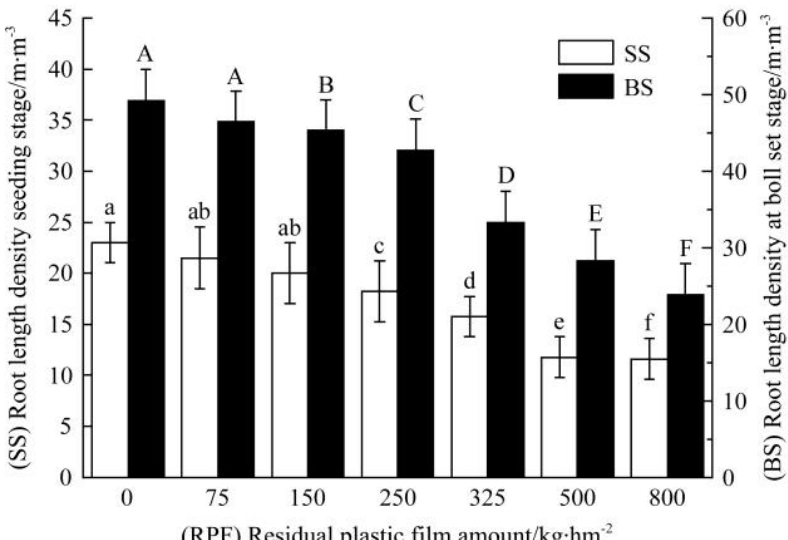

Note: Different lowercase letters indicate a significant difference between the gradient levels in the seedling stage (SS) $(p<0.05)$. Different uppercase letters indicate a significant difference between the gradient levels in the boll set stage (BS) $(p<0.05)$

Figure 5 Effect of residual plastic film on root dry length density at the seedling stage (SS) and the boll set stage (BS)

Soil humidity was measured using a plug-in hygrometer (soil temperature/humidity detector (TDC-220D type sensor; Beijing time Technology Co., Ltd.) that inserted deep into each soil layer. Result showed that soil moisture was closely correlated with the growth of root system and above-ground organs in cotton. In the soil layer $0-10 \mathrm{~cm}$ deep, the moisture content demonstrated a significant $(p<0.01)$ negative correlation with the growth indexes
(Table 5), which indicated that a higher moisture content at this depth is not favorable for cotton growth. As the amount of RPF increased (Table 3$)$, the moisture content in soil top layer $(0-10 \mathrm{~cm})$ increased. In contrast, plant height, root length density, root volume, stem diameter, and root dry mass density were all decreased. Plastic film is a foreign substance that provides no nutrition for crops ${ }^{[26,27]}$. As the amount of RPF increases, the moisture movement in soil is blocked since both soil porosity and soil permeability decrease, which impedes the downward infiltration and the horizontal diffusion of water, finally affect crop roots. Moreover, under strong evaporation, irrigated water gets converted into unavailable water, which inhibits normal root growth in $\operatorname{cotton}^{[28]}$. Evaporation from top soil has a negative effect on root growth that results in reduced root volume, root surface area, and root length ${ }^{[29,30]}$.

Table 5 Correlation analysis of soil moisture contents in different soil layers and characteristics of root system and above-ground organs

\begin{tabular}{cccccc}
\hline $\begin{array}{c}\text { Soil layer } \\
\text { /cm }\end{array}$ & $\begin{array}{c}\text { Root } \\
\text { volume }\end{array}$ & $\begin{array}{c}\text { Root length } \\
\text { density }\end{array}$ & $\begin{array}{c}\text { Root dry } \\
\text { weight }\end{array}$ & $\begin{array}{c}\text { Plant } \\
\text { height }\end{array}$ & $\begin{array}{c}\text { Steam } \\
\text { diameter }\end{array}$ \\
\hline $0-10$ & $-0.978^{* *}$ & $-0.985^{* *}$ & $-0.947^{* *}$ & $-0.99 * *$ & $-0.954^{* *}$ \\
$10-20$ & $0.952^{*}$ & $0.971^{*}$ & $0.936^{*}$ & $0.993 * *$ & $0.940^{*}$ \\
$20-30$ & $0.95 *$ & $0.968^{* *}$ & $0.937 *$ & $0.933^{* *}$ & $0.938^{*}$ \\
\hline
\end{tabular}

3.4 Effect of RPF on plant height and stem diameter

Plant height and stem diameter are two indexes that reflect cotton growth ${ }^{[31,32]}$. In this study, plant height of experimental group T1 to T6 was decreased by $7.2 \%, 15.75 \%, 22.14 \%, 29.34 \%$, $37.26 \%$, and $41.31 \%$ respectively compared to T0 (Figure 6a), significantly decreased with increase in RPF amount. During the boll set stage, the plant height was less than $(0.86,0.79,0.76,0.66$, 0.51 , and 0.44 times) that of T0. Stem diameter of experimental group $\mathrm{T} 1$ to $\mathrm{T} 6$ decreased by $7.21 \%, 8.36 \%, 10.08 \%, 12.96 \%$, $21.91 \%$, and $29.37 \%$ during the seedling stage, and by $4.87 \%$, $5.8 \%, 6.35 \%, 6.82 \%, 14.11 \%$, and $31.31 \%$ during the boll set stage as compared to T0 (Figure 6b).

The RPF exists in the soil. If the cotton seed was in the position of RPF at the time of sowing, the plastic fragments will wrap the cotton seed. On one hand, it will make the cotton root system difficult to grow. On the other hand, it will also make the water and fertilizer harder to move in the soil, affecting the cotton root system to absorb nutrients. This kind of situation is obvious in the farmland with a large amount of RPF. Soil residues influence water and fertilizer absorption, which in turn affect seedling growth in cotton ${ }^{[33]}$. Moreover, cotton root system is generally weak during the seedling stage. Therefore, cotton plants were shorter at higher RPF levels in this study.

To quantify the effect of RPF on cotton growth, the weekly growth rates during the seedling stage and the boll set stage were calculated. During the seedling stage, the growth rates of plant height of experimental group $\mathrm{T} 1$ to $\mathrm{T} 6$ decreased by $6.89 \%$, $7.62 \%, 10.34 \%, 12.64 \%, 21.83 \%$, and $29.88 \%$ respectively compared to T0 (Figure 6c). Variance analysis revealed that at when RPF levels equal to or greater than $300 \mathrm{~kg} / \mathrm{hm}^{2}$, the growth rate of plant height significantly decreased $(p<0.05)$. RPF in the range 300 to $500 \mathrm{~kg} / \mathrm{hm}^{2}$ had a significant effect on cotton growth during the seedling stage. During the boll set stage, the growth rate of plant height of experimental group T1 to T6 decreased by $13.25 \%, 16.57 \%, 18.65 \%, 23.52 \%, 33.89 \%$, and $48.16 \%$ respectively compared to T0 (Figure 6c). The T3 and T6 plant height growth rates were significantly less than that of other 
treatments $(p<0.05)$. During the seedling stage and the boll set stage, plant height decreased as the RPF level increased. In addition, the effect of RPF on plant height during the boll set stage was greater.

During the seedling stage, maximum plant height growth rate was $3.89 \mathrm{~cm} /$ week and maximum stem diameter growth rate was $0.87 \mathrm{~mm} /$ week (Figure 6d); minimum height growth rate was $1.3 \mathrm{~cm} /$ week and minimum stem diameter growth rate was

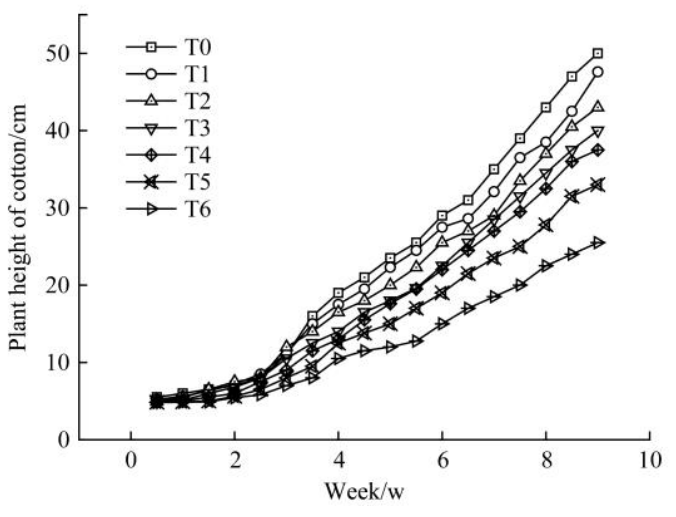

a. Plant height

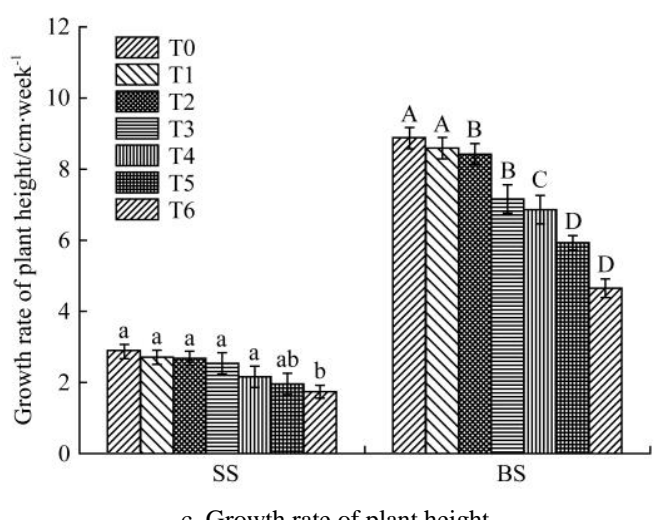

c. Growth rate of plant height
$0.57 \mathrm{~mm} /$ week. During the boll set stage, maximum plant height growth rate was $8.97 \mathrm{~cm} /$ week and maximum stem diameter growth rate was $1.61 \mathrm{~mm} /$ week; minimum plant height growth rate was $4.13 \mathrm{~cm} /$ week and minimum stem diameter growth rate was $0.9 \mathrm{~mm} /$ week (Figure 6d). During both stages, the stem diameter growth rate decreased with increased RPF level. When RPF content above $300 \mathrm{~kg} / \mathrm{hm}^{2}$, the stem diameter growth rate was significantly lower $(p<0.05)$.

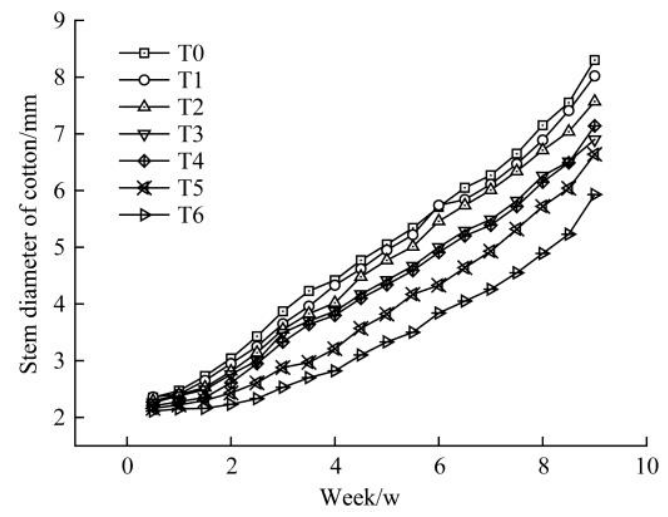

b. Stem diameter

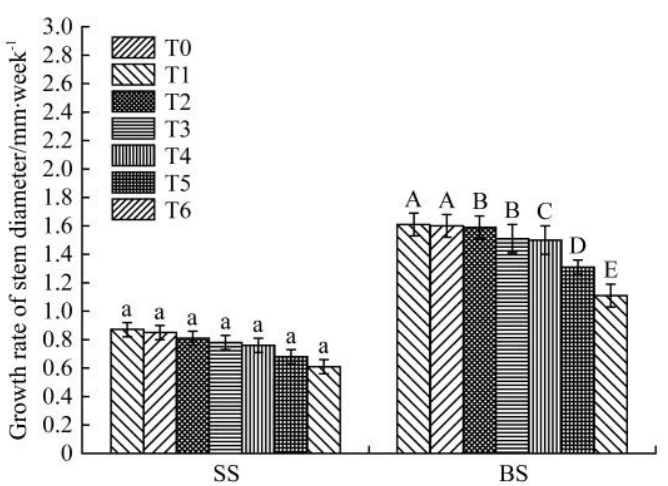

d. Growth rate of stem diameter in cotton

Figure 6 Effects of different amounts of residual plastic film on (a) plant height, (b) stem diameter, (c) growth rate of plant height, and (d) growth rate of stem diameter in cotton

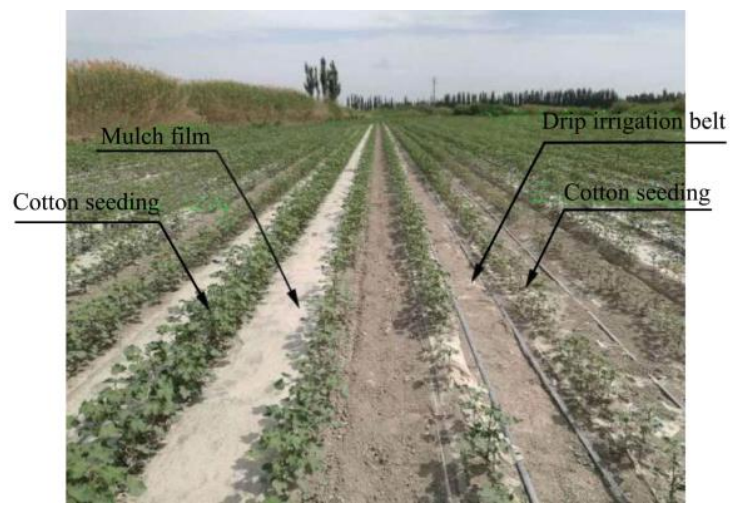

a. Experimental field under plastic film mulching

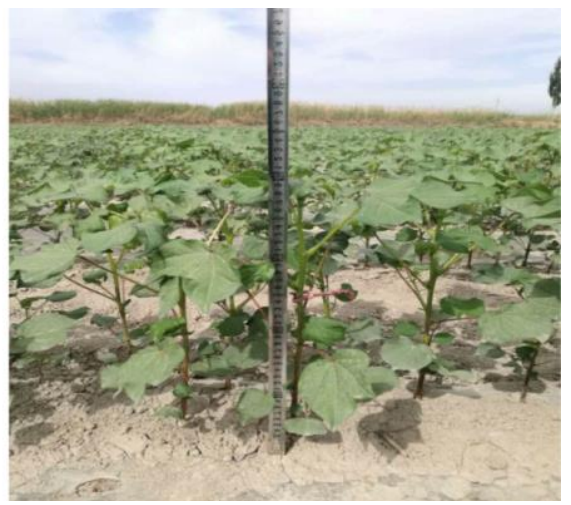

b. Data collection

Figure 7 Plant height and stem diameter of cotton during the seedling stage

\subsection{Effect of RPF on dry matter content}

Below a certain threshold, the dry matter content during the seedling stage apparently correlated with the amount of RPF. Dry matter content of experimental group T1 to T6 decreased by $5.09 \%$, $1.55 \%, 9.14 \%, 31.63 \%, 46.82 \%$, and $41.88 \%$ respectively compared to T0 (Figure 8a). There was no significant difference in the root, stem, or leaf dry matter contents between different RPF levels when its content was below $300 \mathrm{~kg} / \mathrm{hm}^{2}$ (Figure 8a) ( $p$ > 0.05). When RPF levels were above $300 \mathrm{~kg} / \mathrm{hm}^{2}$ (Figure $8 \mathrm{a}$ ), stem dry matter content decreased significantly as RPF level increased $(F=13.21, p<0.05)$ while leaf dry matter content did show a significant difference $(F=2.13, p<0.05)$.

Dry matter content during the boll set stage demonstrated a negative correlation with the RPF level. Dry matter content decreased significantly with increase in RPF level above $300 \mathrm{~kg} / \mathrm{hm}^{2}(F=31.32, p<0.05)$ (Figure $8 \mathrm{~b}$ ). Dry matter content of experimental group T1 to T6 decreased by $6.92 \%, 4.31 \%$, $13.14 \%, 14.26 \%, 23.35 \%$, and $46.32 \%$ respectively compared to 
T0 (Figure 8b). Total dry matter content during the boll set stage was less than that during the seedling stage, which indicated a greater effect of RPF on dry matter content during the boll set stage. During the boll set stage, the root, stem, and flower dry matter contents were all decreased with increase in RPF level, and the leaf dry matter content is the only parameter that showed the opposite trend.

Dry matter content is an important indicator of cotton growth $^{[34,35]}$. During the seedling stage, root and stem dry matter contents, together with soil moisture content, decreased with increase in RPF level, while leaf dry matter content increased gradually. Moreover, cotton is a water-sensitive plant. These changes together promoted abscisic acid generation in the root. Even during water shortage, cotton plants grow normally as the abscisic acid moves to the above-ground organs ${ }^{[36,37]}$ Under these conditions, the number and size of cotton leaves were able to maintain an increasing trend, which results in an increase in leaf dry matter content.
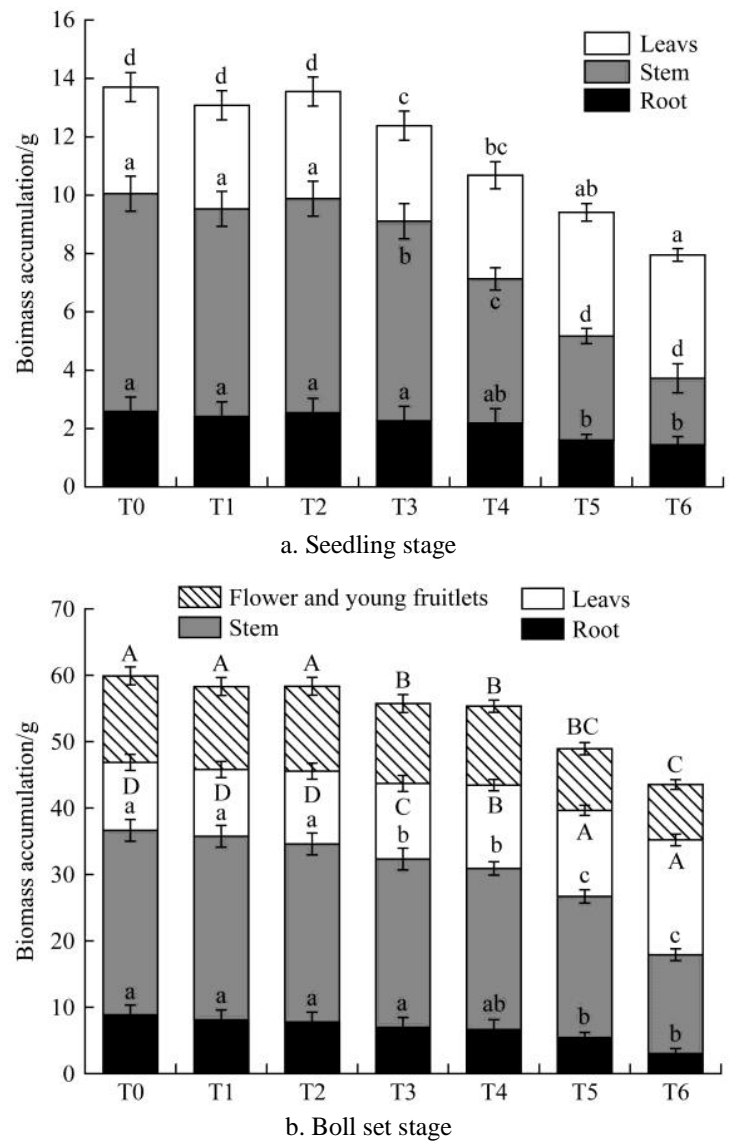

Figure 8 Effects of different amounts of residual plastic film on dry matter content of root, stem, and leaves during seedling and

\section{boll set stages}

\subsection{Effect of RPF on number of bolls and cotton yield}

Above a certain threshold, a decrease in number of bolls with increase in RPF level was observed (Figure 9a). Below $300 \mathrm{~kg} / \mathrm{hm}^{2}$, the effect of RPF on the number of bolls was not significant and the mean number of bolls was 7.8 per plant, which made no difference from the control group. Above $300 \mathrm{~kg} / \mathrm{hm}^{2}$, the effect was significant and the mean number of bolls was 6.1 per plant, $21 \%$ less than that when RPF level was below $300 \mathrm{~kg} / \mathrm{hm}^{2}$ (Figure 9a).

Cotton yield for T0, T1, T2, T3, T4, T5, and T6 at $367.45 \mathrm{~kg} / \mathrm{hm}^{2}, 375.71 \mathrm{~kg} / \mathrm{hm}^{2}, 358.15 \mathrm{~kg} / \mathrm{hm}^{2}, 319.45 \mathrm{~kg} / \mathrm{hm}^{2}$, $297.13 \mathrm{~kg} / \mathrm{hm}^{2}$, and $261.71 \mathrm{~kg} / \mathrm{hm}^{2}$ respectively was recorded in this experiment (Figure 9b). T1 obtained the highest yield while
T6 got the lowest yield. When RPF levels in the range of 0$150 \mathrm{~kg} / \mathrm{hm}^{2}$, the effect of RPF on cotton yield was not significant. When RPF level was higher than $200 \mathrm{~kg} / \mathrm{hm}^{2}$, its negative effect on cotton growth was start to be significant. When RPF level reached $500 \mathrm{~kg} / \mathrm{hm}^{2}$, the cotton yield decreased by $27.07 \%$ compared to T0 $\left(0 \mathrm{~kg} / \mathrm{hm}^{2}\right)$.
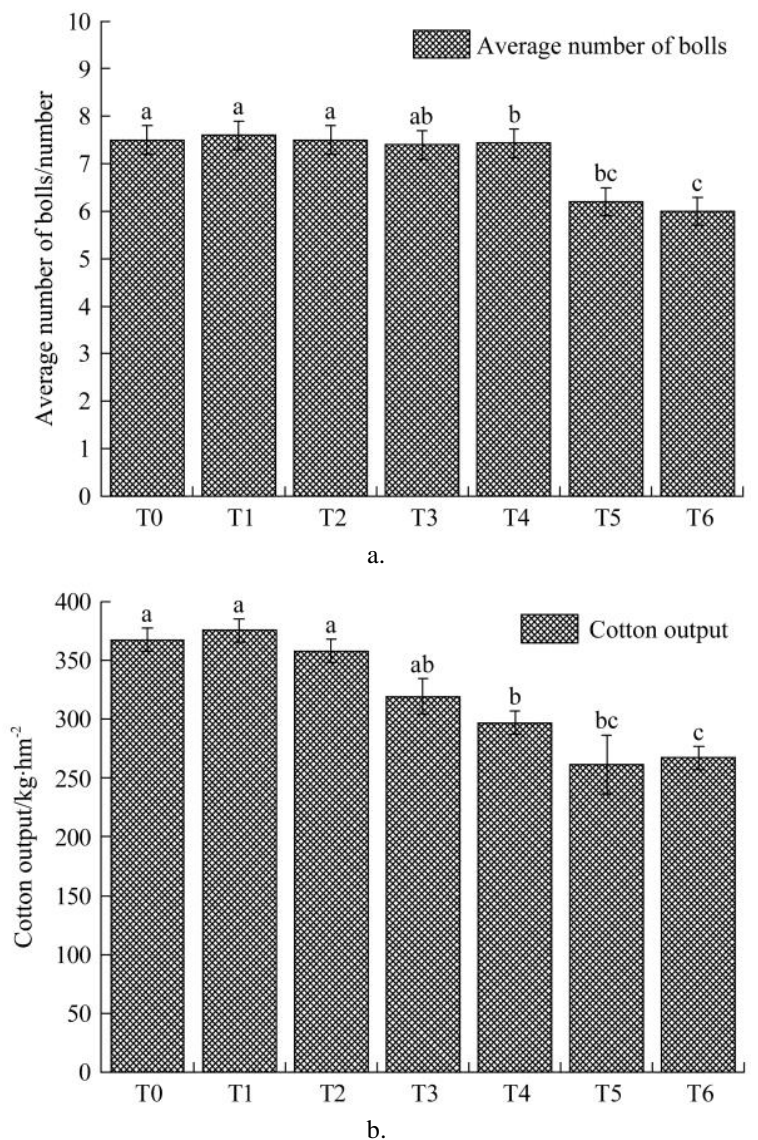

Figure 9 Effects of different amounts of residual plastic film on (a) number of bolls and (b) cotton yield

Yield is an important indicator of productivity in cotton. The increase in residual film had adverse effects on root, leaf, and stem of cotton, which led to a decrease in the number/size of cotton bolls RPF at different densities have different effects on soil water movement, which influences the distribution of the matter in roots and other organs ${ }^{[38,39]}$, inhibits root growth, and reduces the contact area between root and soil. This may directly lead to abnormal growth and precocity of the cotton. Plastic residues in the soil influence water and fertilizer absorption, which in turn affects root growth and leads to early crop maturity. Eventually, flower and boll numbers and single boll weight decrease, which result in yield drop. Based on these findings, it is concluded that soil residual film levels above $200 \mathrm{~kg} / \mathrm{hm}^{2}$ (threshold level) significantly affect cotton yield. It is also suggested that the effect of RPF on cotton can be measured using several indexes, including boll number, single boll weight, and actual yield.

\section{Conclusions}

RPF significantly affects the distribution and movement of moisture in the soil. Rapid evaporation of moisture from top soil inhibits the ability of cotton to absorb water and fertilizers. Above a certain threshold level, RPF demonstrated adverse effects on germination rate, seedling survival rate, root volume, root length density, plant height, dry matter content, and yield in cotton. RPF at levels above $250 \mathrm{~kg} / \mathrm{hm}^{2}$ demonstrated significant effects on both 
germination rate and seedling survival rate at the initial stages and on root volume and root length density during both the seedling stage and the boll set stage. At RPF levels above $300 \mathrm{~kg} / \mathrm{hm}^{2}$, stem dry matter content decreased significantly. During the boll set stage, root, stem, and flower dry matter contents decreased with increase in RPF level; however, leaf dry matter content increased. At levels above $200 \mathrm{~kg} / \mathrm{hm}^{2}$, RPF demonstrated a negative effect on cotton yield. In summary, RPF at levels above $200 \mathrm{~kg} / \mathrm{hm}^{2}$ had a significant negative effect on cotton growth. To assess and control RPF pollution, $200 \mathrm{~kg} / \mathrm{hm}^{2}$ was recommended as a threshold level in the soil for cotton cultivation. This study provided useful information for the management of soil pollution caused by RPF as well as for soil restoration.

\section{Acknowledgements}

This work was financially supported by National key R \& D plan of China (No. 2017YFD0701102), the Corps key R \& D projects (No.2019AB007), the Special Fund for Agroscientific Research in the Public Interest (No. 201503105), and the National Natural Science Foundation of China (Grant No. 11562019). The authors are grateful to the farmers of the trial area for their cooperation.

\section{[References]}

[1] Yan C, He W, Turner N C. Plastic-film mulch in Chinese agriculture: importance and problems. World Agriculture, 2014; 4(2): 32-36.

[2] Lament W J. Plastic mulches for the production of vegetable crops. Horttechnology, 1993; 3: 35-39.

[3] Kyrikou I, Briassoulis D. Biodegradation of agricultural plastic films: A critical review. Journal of Polymers and the Environment, 2007; 15(3): 125-150.

[4] Erenstein O. Crop residue mulching in tropical and semi-tropical countries: an evaluation of residue availability and other technological implications. Soil \& Tillage Research, 2002; 67(2): 115-133.

[5] Liu J G, Li Y B, Zhang W, Sun Y Y. The distributing of the residue film and influence on cotton growth under continuous cropping in oasis of Xinjiang. Journal of Agro-Environment Science, 2010; 29(02): 246-250. (in Chinese)

[6] Bu L D, Liu J L, Zhu L, Luo S S, Chen X P, Li S Q. The effects of mulching on maize growth, yield and water use in a semi-arid region. Agricultural Water Management, 2013; 123: 71-78.

[7] Yan C R, He W Q, Liu E K, Lin T, Mormile P, Liu S. Concept and estimation of crop safety period of plastic film mulching. Transactions of the CSAE, 2015; 31(09): 1-4. (in Chinese)

[8] Liu Q F, Chen Y, Liu Y, Wen X X, Liao Y C. Coupling effects of plastic film mulching and urea types on water use efficiency and grain yield of maize in the Loess Plateau, China. Soil \& Tillage Research, 2016; 157: $1-10$.

[9] Wang X F, Hu C, Lu B, Jiang J Y, Hou S L. Wind tunnel test on damages of plastic film under the wind-sand effect in south Xinjiang of China. International Agricultural Engineering Journal, 2017; 26(04): 16-23.

[10] Yan C R, Wang X J, He W Q, Ma H, Cao S L, Zhu G F. The residue of plastic film in cotton fields in Shihezi Xinjiang. Acta Ecologica Sinica, 2008; 28(07): 470-474. (in Chinese)

[11] Dong H G, Liu T, Li Y G, Liu H F, Wang D. Effects of plastic film residue on cotton yield and soil physical and chemical properties in Xinjiang. Transactions of the CSAE, 2013; 29(08): 91-99. (in Chinese)

[12] Cuello J P, Hwang H Y, Gutierrez J, Kim S Y, Kim P J. Impact of plastic film mulching on increasing greenhouse gas emissions in temperate upland soil during maize cultivation. Applied Soil Ecology, 2015; 91: 48-57.

[13] Huo L, Pang H C, Zhao Y G, Wang J, Lu C, Li Y Y. Buried straw layer plus plastic mulching improves soil organic carbon fractions in an arid saline soil from Northwest China. Soil \& Tillage Research, 2017; 165: 286-293.

[14] He H J, Wang Z H, Guo L, Zheng X R, Zhang J Z, Li W H. Distribution characteristics of residual film over a cotton field under long-term film mulching and drip irrigation in an oasis agroecosyste. Soil \& Tillage Research, 2018; 180: 194-203.
[15] Hu C, Hu Y S, Wang X F, Wang W, Lu B, Liu C J. Effect of residual plastic films on survival rate of cotton seeds in South Xinjiang. International Agricultural Engineering Journal, 2017; 26(1): 19-25.

[16] Jin X X, An T T, Gall A R, Li S Y, Sun L J, Pei J B, et al. Long-term plastic film mulching and fertilization treatments changed the annual distribution of residual maize straw $\mathrm{C}$ in soil aggregates under field conditions: Characterization by $\mathrm{C}-13$ tracing. Journal of Soils and Sediments, 2018; 18(1): 169-178.

[17] Dong H G, Liu T, Han Z Q, Sun Q M, Li R. Determining time limits of continuous film mulching and examining residual effects on cotton yield and soil properties. Journal of Environmental Biology, 2015; 36: e677-e684.

[18] Yan C R, Mei X R, He W Q, Zheng S H. Present situation of residue pollution of mulching plastic film and controlling measures. Transactions of the CSAE, 2006; 22(11): 269-272. (in Chinese).

[19] He W Q, Yan C R, Liu S, Chang R Q, Wang X J, Cao S L. The Use of Plastic Mulch Film in Typical Cotton Planting Regions and the Associated Environmental Pollution. Journal of Agro-Environment Science, 2009; 28(8): 1618-1622. (in Chinese)

[20] Hou S L, Hu S Y, Kong J M, Zhang H Y, Na M J, Dong X. Present situation of Research on plastic film residue collector in China. Transactions of the CSAE, 2002; 18(3): 186-190. (in Chinese)

[21] Chen B Q, Yan C R, Garre S, Mei X R, Liu E K. Effects of a 'one film for 2 years' system on the grain yield, water use efficiency and cost-benefit balance in dryland spring maize (Zea mays L.) on the Loess Plateau, China. Archives of Agronomy and Soil Science, 2018; 64(7): 939-952.

[22] Xie J H, Hou S L, Fu Y, Na M J, Zhang H Y. Motion analysis and Experiment on spring-tooth mulching plastic film collector. Transactions of the CSAE, 2013; S1: 94-99. (in Chinese)

[23] Zhao Y, Chen X G, Wen H J, Zheng X, Niu Q, Kang J M. Research status and prospect of control technology for residual plastic film pollution in farmland. Transactions of the CSAM, 2017; 48(6): 1-12. (in Chinese)

[24] Niu R K, Wang X F, Hu C, Hou S L, Lu B, Li J B. Analysis of the current situation of plastic films residue pollution of cotton field in Xinjiang Aksu area. Xinjiang Agricultural Sciences, 2016; 31(2): 283-288. (in Chinese)

[25] Li Y Q, He W Q, Yan C R, Guo R, Zhao C X. Effects of Agricultural Plastic Residual Films on Morphologic and Physiological Characteristics of Root System of Cotton and Maize in Seedling Stage. Journal of Agricultural Resources and Environment, 2017; 34(2): 108-114. (in Chinese)

[26] Kasirajan S, Ngouajio M. Polyethylene and biodegradable mulches for agricultural applications: A review. Agronomy for Sustainable Development, 2012; 32: 501-529.

[27] Jiang X J, Liu W, Wang E, Zhou T, Xin P. Residual plastic mulch fragments effects on soil physical properties and water flow behavior in the Minqin Oasis, northwestern China. Soil \& Tillage Research, 2017; 166: $100-107$.

[28] Liu E K, He W Q, Yan C R. 'White revolution' to 'white pollution'-agricultural plastic film mulch in China. Environmental Research Letters, 2014; 9(9): 207-260.

[29] Wan Y, El-Swaify S A. Run off and soil erosion as affected by plastic mulch in a Hawaiian pineapple field. Soil \& Tillage Research, 1999; 52: 29-35.

[30] Zou X Y, Niu W Q, Liu J J, Li Y, Liang B H, Guo L L. Effects of residual mulch film on the growth and fruit quality of tomato (Lycopersicon esculentum Mill.). Water Air and Soil Pollution, 2017; 228: 71.

[31] Lamont W J. Plastics: Modifying the microclimate for the production of vegetable crops. Horttechnology, 2005; 15(3): 477-481.

[32] Kim G. W, Das S, Hwang H Y, Kim P J. Nitrous oxide emissions from soils amended by cover-crops and under plastic film mulching: fluxes, emission factors and yield-scaled emissions. Atmospheric Environment, 2017; 152: 377-388.

[33] Yang N, Sun Z X, Feng L S, Zheng M Z, Chi D C, Meng W Z. Plastic film mulching for water-efficient agricultural applications and degradable films materials development research. Materials and Manufacturing Processes, 2015; 30: 143-154

[34] Sun H Y, Zhang X Y, Chen S Y, Shao L W, Wang Y Z, Liu K T. Effects of deficit irrigation on physio-ecological indices of winter wheat. Chinese Journal of Eco-Agriculture, 2011; 19(05): 1086-1090. (in Chinese)

[35] Cakir R. Effect of water stress at different development stages on vegetative and reproductive growth of corn. Field Crops Research, 2004; 89(1): $1-16$ 
[36] Anikwe M A N, Mbah C N, Ezeaku P I, Onyia V N. Tillage and plastic mulch effects on soil properties and growth and yield of cocoyam (Colocasia esculenta) on an ultisol in southeastern Nigeria. Soil \& Tillage Research, 2007; 93: 264-272.

[37] Han G J, Chen N L, Li J X, Zhang K, Guo Y H, Fang C Y. Response of stomatal conductance and osmotic adjustment substance accumulation to rapid drough stress in tomato leaves. Chinese Journal of Eco-Agriculture, 2013; 21(9): 1100-1106. (in Chinese)
[38] Cai T, Zhang C, Huang Y, Huang H, Yang B, Zhao Z, et al. Effects of different straw mulch modes on soil water storage and water use efficiency of spring maize (Zea mays L.) in the Loess Plateau of China. Plant Soil and Environment, 2015; 61(6): 253-259.

[39] Wang L, Lin T, Yan C R, He W Q, Wang J, Tang Q X. Effects of different film residue and irrigation quota on nutrient and water use efficiency of cotton under drip irrigation. Journal of Plant Nutrition, 2018 24(1): 122-133. (in Chinese) 